\title{
MODA INCLUSIVA, RECONHECENDO A NECESSIDADE DA CRIANÇA CADEIRANTE
}

Rosângela Elisa de Sousa

Centro Universitário de João Pessoa - UNIPÊ

roselisa1@live.com

Lucyana Azevedo Xavier

Centro Universitário de João Pessoa - UNIPÊ

lucyana.azevedo@unipe.br

Suellen Silva de Albuquerque

Centro Universitário de João Pessoa - UNIPÊ

suellen.albuquerque@unipe.br

Resumo: Este projeto aborda a inclusão social, como um recurso a ser estimulado através do desenvolvimento de produtos de moda. Levando em conta esta demanda de mercado a pesquisa, integrante do projeto, identificou aspectos de uso, acessibilidade, conforto e a percepção dos pais e terapeutas no que tange ao vestir, despir e o cognitivo da criança em relação ao vestuário. O público-alvo pesquisado neste projeto foram crianças cadeirantes, com faixa-etária entre oito a doze anos, os pais e profissionais na área de saúde, como: Fisioterapeutas, Educador Físico, Terapeuta Ocupacional e Psicólogos, integrantes das instituições, CEAEHH Centro de Atividades Especiais Helena Holanda e FUNAD - Fundação Centro Integrado de Apoio ao Portador de Deficiência, localizadas na cidade de João Pessoa - PB, apoiadores deste projeto através da cessão da infraestrutura e acesso ao público. Os dados obtidos resultaram no desenvolvimento de uma coleção de moda com modelagem diferenciada, versatilidade de usos aliada a um referencial estético que priorizou a inclusão da criança cadeirante na sociedade, através do uso das tendências de mercado usuais no segmento infantil.

Palavras-chave: Design, Moda inclusiva, Crianças, Cadeirante. 


\section{INTRODUÇÃO}

O segmento de mercado, moda inclusiva, é relativamente novo. Encontrar livros e estudos com profundidade no tema é tarefa árdua, por outro lado, identificar pessoas cadeirantes é uma constante, assim como crianças cadeirantes em escolas, parques, cinemas e em vários locais da cidade e etc. Levando em conta esta demanda de mercado este projeto, objetivou através da identificação de aspectos de uso, acessibilidade e conforto incluir no cenário da moda infantil esses consumidores, por possuir grande amplitude de possibilidades ainda tão pouco difundidas no mercado.

O vestuário, e por consequência a moda, foram ícones de mudanças que revolucionaram a forma de pensar da sociedade. Ao aprofundar o conhecimento nas principais diretrizes que deram origem ao termo moda, nos afastamos da percepção de criação inicial da indumentária, é preciso rever conceitos e sugerir que a moda contemporânea identifique, com eficiência, suas necessidades latentes da sociedade. Quando o homem primitivo pensou na roupa como recurso para se proteger do frio, ele, desenvolveu um objeto que facilitou a sua vida e da humanidade, identificou e solucionou um problema. Seguindo este mesmo princípio, este projeto valoriza o papel fundamental do Designer, identificar e proporcionar soluções inovadoras, neste projeto direcionado ao segmento da moda inclusiva infantil.

A moda faz parte do mundo das crianças, elas consomem roupas e acessórios de seus heróis favoritos, através do universo das histórias infantis em programas na televisão, em cinemas e em mídias diversas. Por isso, a coleção inclusiva teve como um dos requisitos atender à necessidade desses consumidores e promover a inclusão através da moda.

Para identificar os aspectos técnicos referente as necessidades das crianças cadeirantes utilizamos os métodos de pesquisa dos tipos: qualitativa, quantitativa, bibliográfica, exploratória e explicativa. Classificamos neste projeto os participantes da pesquisa como: Grupo 1 - Pais de crianças cadeirantes; Grupo 2 - Profissionais da área de saúde, Fisioterapeutas, Psicólogos, Assistente Social, e Profissionais Multidisciplinares que atuam nas instituições e por fim, o Grupo 3 - Crianças cadeirantes de 8 a 12 anos. 0 contato direto com as crianças, pais e profissionais foi fundamental para identificar as dificuldades sobre o uso das roupas, no que tange aos recortes, modelagens, costuras, fechamentos, aberturas, vestir e despir. A pesquisa resultou na definição de requisitos e parâmetros para o desenvolvimento da coleção, composta por quinze looks, dos quais, cinco foram prototipados.

O projeto apresentou inovação em modelagens e versatilidade de usos aliada a um referencial estético que priorizou a inclusão da criança cadeirante na sociedade, revisitando as tendências de mercado de roupas infantis, utilizou como método o desenvolvimento de painéis imagéticos que ilustrou os personagens infantis mais citados pelas crianças participantes da pesquisa.

A moda necessita ser uma porta aberta para a inclusão, para que isto aconteça basta que tenhamos uma percepção de inclusão social como regra da sociedade, em todas as áreas. A inclusão social deve ser priorizada pela sociedade, sendo a roupa mais um recurso para tal. A indumentária deve ajudar a sociedade na construção de suas histórias e neste cenário precisamos olhar com grande preocupação os aspectos sociais e psicológicos que o vestuário provoca, influenciando no bem-estar das pessoas. 


\section{DESENVOLVIMENTO}

No início da história da humanidade não há muitos relatos sobre a infância. Apenas um pouco antes da Idade Média é que surgem os primeiros relatos de como elas viviam, se comportavam e se vestiam na sociedade. A pesquisa bibliográfica apresentou de forma simplificada um passeio através dos séculos, iniciando no Século XIV até Século XXI, e observou aspectos da vestimenta infantil, já que não identificamos registros sobre a vestimenta para a criança cadeirante.

Diante de todo relato da história por longos séculos, notamos que o reconhecimento das necessidades da infância foi ignorado por muito tempo, desde o nascimento, onde a criança era praticamente torturada por está constantemente envolta em cueiros e faixas apertadas, até a falta do olhar carinhoso e preocupado com o seu bem-estar.

Apesar de um longo caminho já percorrido no desenvolvimento do vestuário, ainda, é fácil identificar falhas no processo de desenvolvimento das coleções quando tratamos da infância, os padrões que as indústrias impõem ao mercado estão fora da realidade da criança cadeirante, especificamente, no que se refere aos tamanhos, modelagens, biótipos e necessidades. Portanto, o projeto foi delimitado para melhor atender os objetivos e propôs uma solução comercial ao vestuário infantil direcionado a criança cadeirante, conforme etapas e métodos adotados descritos a seguir.

\subsection{Metodologia}

Esta pesquisa se apropriou de vários métodos, iniciando pela pesquisa bibliográfica, conforme explica Severino (2007, p.122), utiliza-se de dados ou de categorias teóricas, já trabalhados por outros pesquisadores e devidamente registrados. Os textos tornam-se fontes dos temas a serem pesquisados. Especificamente para este projeto a pesquisa bibliográfica utilizou referências sobre a história do vestuário infantil, ergonomia, moda inclusiva, modelagens, criações de coleção e sociologia aplicada a moda.

Adotou-se, ainda, uma pesquisa de campo com método qualitativo e quantitativo, através do uso de questionário semiestruturado, para identificar as necessidades do público, a partir do ponto de vista dos pais e profissionais da área de saúde que trabalham diretamente com crianças cadeirantes. Samara e Barros (2002, p.30), explicam que a pesquisa do tipo quantitativa tem o objetivo de responder questões do tipo "Quanto?", utilizando uma amostra especifica da população como parâmetro para a análise de dados.

Partindo dos dados obtidos na pesquisa de campo, foi desenvolvida a terceira etapa, que contemplou a elaboração de peças de roupas, denominadas mockups, que foram apresentadas as crianças cadeirantes, através do método exploratório. Para essa pesquisa adotamos o método descrito por Severino (2007, p.123) que diz: “A pesquisa exploratória busca apenas levantar informações sobre um determinado objeto, delimitando assim um campo de trabalho, mapeando as condições de manifestação desse objeto".

A pesquisa exploratória teve como objetivo observar o procedimento de vestir e despir as crianças, utilizando a modelagem desenvolvida, que tomou como referencias aspectos apontados pela pesquisa com o grupo 1 e 2 . 0 procedimento foi realizado a partir do consentimento dos pais que também participaram da ação, apoiando os filhos. Este projeto de pesquisa com seres humanos seguiu as normas e 
diretrizes da Resolução 466/12, do Conselho Nacional de Saúde, que visa assegurar os direitos e deveres que dizem respeito aos participantes da pesquisa, à comunidade científica e ao Estado, previamente aprovada pelo Comitê de Ética e Pesquisa da instituição de ensino.

O método de criação foi guiado pelo estudo de modelagem. As estampas, cores e aplicações foram influenciados pela pesquisa imagética, que representou o universo infantil, heróis favoritos, histórias de cinemas e em mídias diversas, conforme descreveu Treptow (2013), quando afirma que o estilista deve buscar diversas fontes de informações para apoiar suas ideias, usando o processo de decodificar, interpretar e adaptar as informações. Este processo foi executado a partir da criação de quinze painéis de inspiração, que representou através de imagens o universo infantil.

\subsection{Moda Inclusiva}

Novos horizontes estão sendo implantados, profissionais em design de moda tem se esforçado para dar um novo conceito para a moda, buscando sustentabilidade e inclusão, enquanto o grandioso e amplo mercado das possíveis diferenças espera essa evolução chegar às prateleiras das lojas.

A moda inclusiva sendo ligada a uma nova inteligência, desenvolvendo a capacidade de evolução, trabalhando com à criação de conceitos que envolve o ser humano e não apenas uma classe social, um estilo ou um determinado segmento de mercado. Para alguns designers, que se preocupam com a aplicação dos seus conhecimentos e técnicas, vem utilizando na moda um novo conceito, que renasce de um período pré-histórico, onde a vestimenta era criada para beneficiar o corpo, proteger e agregar valores de usabilidade e não apenas da estética.

\footnotetext{
O sentimento de pertencer ou estar com e para alguém numa sociedade de consumo implica o uso de símbolos e sinais de aparência. A marca de moda é carteira de identidade, não só desta era pós-moderna, como em todo o decorrer da história da humanidade. Revendo meus estudos sobre a trajetória dos estudos sobre o comportamento do consumo, posso afirmar que o indivíduo expressa sua essência por meio de aspectos simbólicos presentes na aparência adornada. (MIRANDA, 2008, p. 110).
}

Ajudar pessoas que tem o direito de vestir-se com qualidade atendendo suas necessidades e facilitando o seu dia-a-dia. Todos têm o direito de sentir-se bem ao vestir uma roupa, seja no conforto, ou na estética.

De acordo com a OMS (Organização Mundial de Saúde), em torno de $10 \%$ da população mundial é de pessoas com deficiência, ou seja, excluídas dos padrões da beleza. No Brasil, dados do IBGE de 2010 apontam que 45,6 milhões de brasileiros possuem algum tipo de deficiência, sendo 9 milhões só no Estado de São Paulo, ou seja, $23,9 \%$ da população brasileira.

\subsection{Ergonomia}

O estudo continuou a ser aprofundado através da pesquisa sobre ergonomia, que é um dos fatores primordiais para o desenvolvimento de qualquer aspecto relacionado ao produto, neste caso em específico observando em detalhes, o usuário deficiente físico cadeirante. 
É de suma importância que a indumentária específica da pessoa hemiplégica, possua características da moda que viabilizem a participação do indivíduo em um certo segmento sociocultural, além de não comprometer sua saúde. (GRAVE, 2010, p.16)

Outro ponto fundamental está ligado diretamente a criatividade do Design que deve conciliar a ergonomia a métodos de confecção. $O$ vestuário deve atender as necessidades do público-alvo através de medidas volumétricas e lineares, através de biótipos como endomorfo, mesomorfo e ectomorfo (Ciência que estuda as medidas do corpo humano para diferentes tipos de pessoas).

Houve ainda a percepção dos aspectos cognitivos das crianças em relação ao vestuário. A estética da roupa influência na autoestima e quando não agradável pode provocar sentimento de tristeza e até stress, refletindo negativamente nos tratamentos. Endossado pelo relato de uma profissional em Terapia Ocupacional que participou da pesquisa, que diz: "O momento emocional da criança influencia muito na terapia". Consideramos que a roupa pode ocasionar um desconforto psicológico já relacionado ao cognitivo, percepção do mundo que a cerca, e principalmente o desconforto físico quando relacionado ao corpo.

Podemos afirmar que, para o desenvolvimento de uma peça de vestuário com qualidade, preocupação ergonômica e com uma percepção cognitiva adequada as necessidades da criança deficiente físico cadeirante foi necessária a utilização de técnicas especificas, adquirida através de um estudo ergonômico e estético.

\subsection{Resultados e discussões}

Com base no método descrito a pesquisa obteve resultados objetivos com dados sociodemográficos, estilo de vida, hábitos de consumo - moda, e dados subjetivos, como as dificuldades do uso de vestuário tradicional pela criança DFC e a relação da ergonomia cognitiva com o vestuário. A pesquisa revelou que nenhuma das mães e/ou pais, grupo 1, entrevistados tem informações relacionadas à moda inclusiva, desconhecem meios que poderiam facilitar suas vidas e de seus filhos. Revelou ainda, a dependência das crianças no ato de vestir e despir, reforçando a hipótese de que o público infantil de crianças cadeirantes se beneficiará com a criação de uma coleção de vestuário pensada para elas, a partir do estudo de suas necessidades e a interação com os seus pais, que compram e auxiliam os filhos no ato de vestir e despir.

A pesquisa com os profissionais, definido como Grupo 2, apresentou a necessidade do desenvolvimento de um vestuário específico para uso nas terapias, que além de proporcionar o conforto, permita a interação da criança, estimulando o desenvolvimento ergonômico cognitivo.

\subsubsection{Modelagem}

A aplicação do método qualitativo e quantitativo, na entrevista com os pais e profissionais norteou o desenvolvimento de mockups, que foram desenhados e modelados a partir da identificação das dificuldades que são acometidos no públicoalvo, como: redução da massa muscular, deformações no corpo, aumento do osso externo, atrofia muscular, espasmo, rigidez dos membros superiores e inferiores. Diante da constatação foi desenvolvido um novo padrão de modelagem, partindo da ergonomia do deficiente cadeirante e suas principais patologias. Analisamos as principais características do corpo afetado pela rigidez muscular e possíveis deformações. 
A figura 1 demonstra o caminho percorrido no processo de criação dos looks, apontamos no esboço do corpo infantil as áreas que apresentam maior rigidez e atrofia em decorrencia da doença, seja ela paralisia cerebral, a mais incidente no grupo pesquisado, ou outra condição que impede a criança de andar.
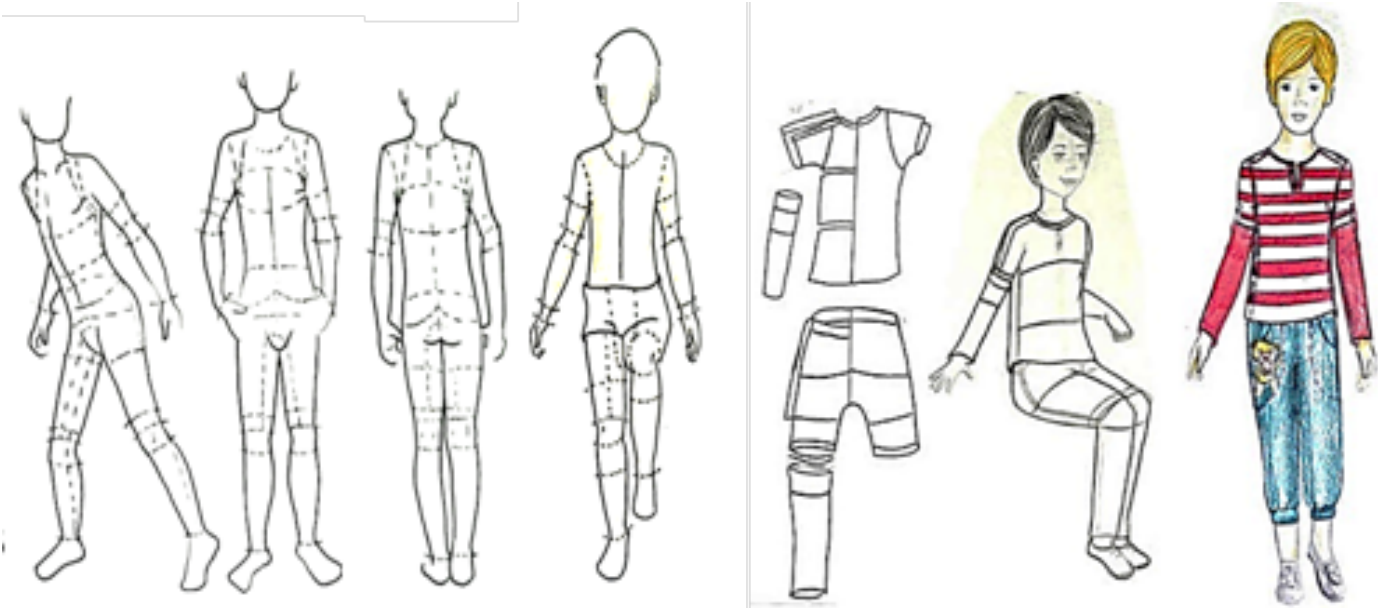

Figura 1 - Prancha demonstrando processo criativo a partir do estudo do corpo infantil. Fonte: Elaborado pelo autor, com base na pesquisa realizada.

A criação dos mockups em escala real foi uma das mais importantes etapas para o desenvolvimento da coleção. Em todos os esboços criados inicialmente foram respeitadas as diretrizes do estudo ergonômico do corpo da criança cadeirante, pensando nas possíveis deformações. Para interagir com o corpo, o vestuário precisa apresentar características que auxiliem o movimento; a cada ação o corpo reage em formas gravitacionais, e o vestuário precisa está adaptado para proporcionar conforto a ação do corpo aos movimentos, realizados conscientemente ou não, pois quando tratamos de um público com necessidades especiais devemos levar em considerações movimentos involuntários como os espasmos musculares, frequente em patologias que levam uma criança ao uso de cadeira de rodas.

A pesquisa exploratória, conforme ilustrado na figura 2, obteve autorização de registro fotográfico, através da assinatura do termo de uso de imagem pelos pais e/ou responsáveis pelas crianças.
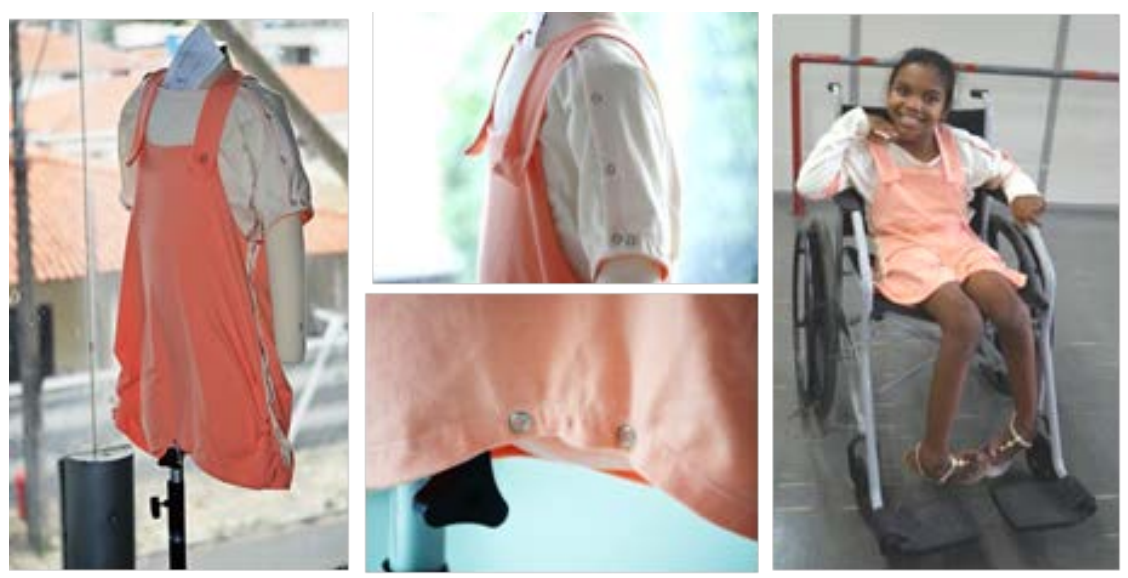

Figura 2 - Mockup feminino e registro fotográfico da pesquisa exploratória. Fonte: Elaborado pelo autor, com base na pesquisa realizada. 
Consideramos o vestuário como uma segunda pele, extensão do corpo, devendo permitir flexões anatômicas e tornar-se intima com o corpo para proporcionar conforto e bem-estar. A pesquisa exploratória permitiu a identificação de pontos de melhoria no produto e que foram considerados para a confecção dos protótipos finais, assim conclui-se que o método, o processo e o produto permitiram atingir os resultados esperados, demonstrados na figura 3, que representa a coleção completa, e figura 4, imagem de um dos looks prototipados em editorial de moda.

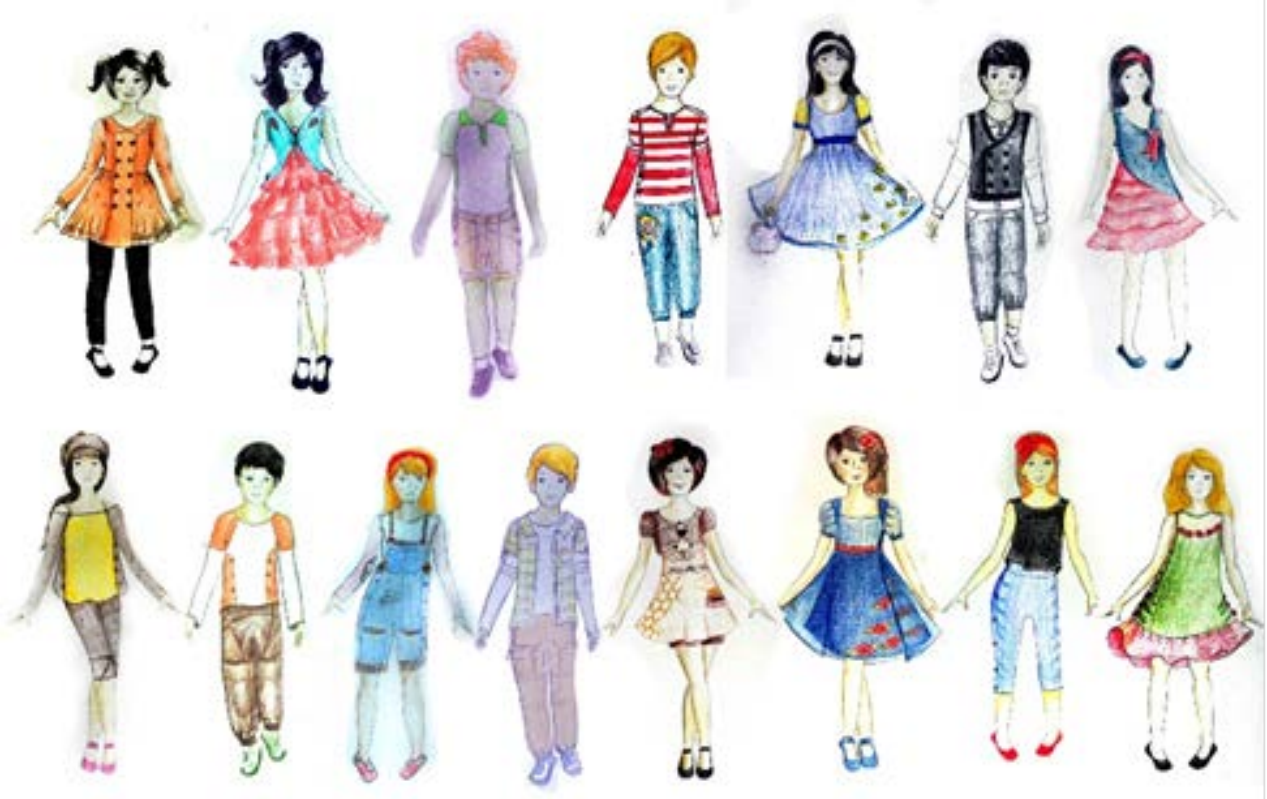

Figura 3 - Prancha única com a coleção completa.

Fonte: Elaborado pelo autor, com base na pesquisa realizada.

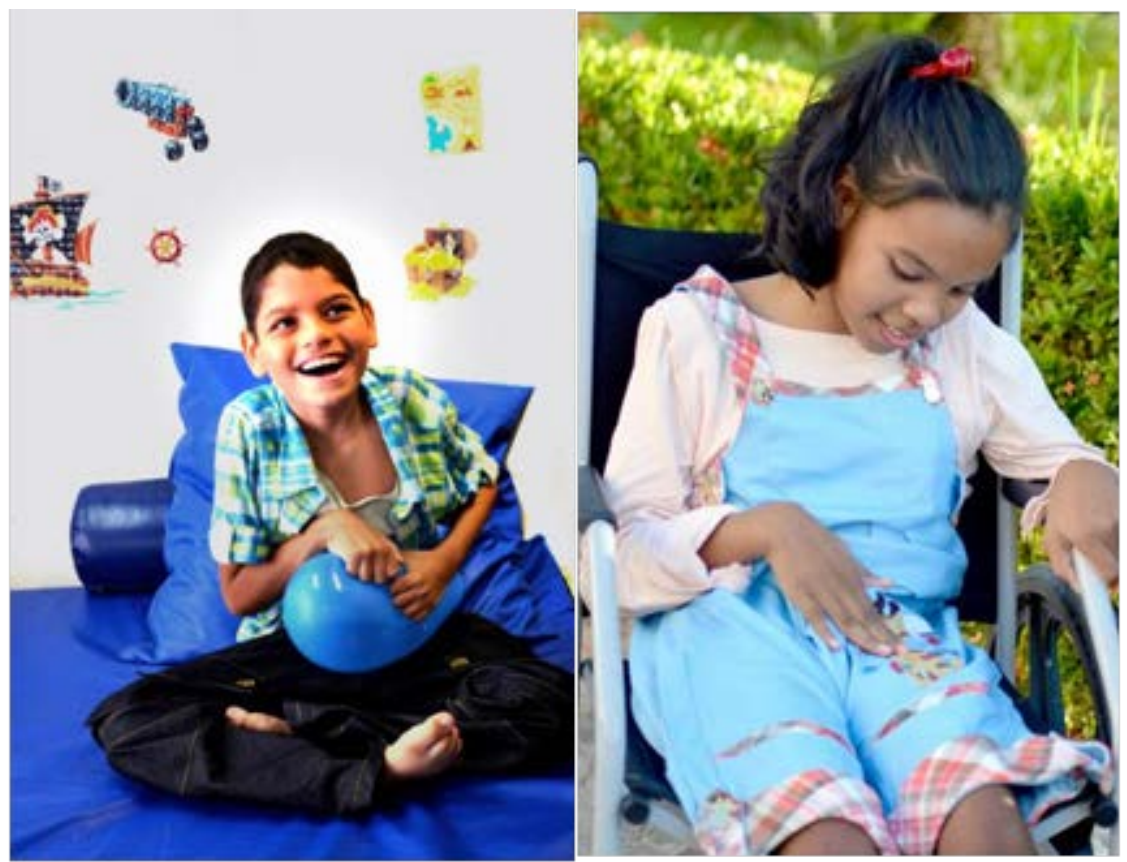

Figura 4 - Protótipos de dois looks da coleção.

Fonte: Elaborado pelo autor, com base na pesquisa realizada. 


\section{CONCLUSÃO}

A pesquisa resultou no desenvolvimento de quinze looks, masculinos e femininos, com modelagem que facilita o vestir e despir da criança. Utilizando recursos de montagem, botões de pressão e transpasses, evitando assim o uso de velcro e outros acessórios tradicionais que possam gerar incomodo e machucar as crianças.

Os modelos desenvolvidos apresentam abertura lateral e frontal, que possibilita aos cuidadores maior facilidade no manejo do vestir e despir. As peças se adaptam ao corpo, pois a modelagem foi pensada para gerar conforto, e apresentam ainda, recortes em pontos estratégicos como: quadril, joelhos, cotovelos, virilha e axilas.

O mundo infantil está presente na coleção através das estampas lúdicas, com cores suaves dentro da cartela de cores extraída da pesquisa imagética e da cartela Pantone 2016, utilizada como tendência para a coleção.

O projeto proporcionou um olhar diferenciado sobre a moda inclusiva infantil, buscou contribuir com o direito de vestir-se com qualidade atendendo suas necessidades e facilitando o dia-a-dia do público-alvo e por consequência das famílias também. Todos têm o direito de sentir-se bem ao vestir uma roupa, seja no conforto, ou na estética.

A pesquisa revelou ainda a necessidade de novos estudos para desenvolvimento de vestuário específico para uso em terapias, que auxiliem a interação da criança com os profissionais, estimulando o desenvolvimento cognitivo, principalmente de crianças com paralisia cerebral.

\section{REFERÊNCIAS}

ARIÈS, Philippe. História social da criança e da família. Trad. Dora Flaksman. 2aa edição. Rio de Janeiro: Zahar Editores, 1981. p.279

GRAVE, Maria de Fátima. A moda-vestuário e a ergonomia do hemiplégico. Escrituras Editora, 2010.

MIRANDA, Ana Paula de. Consumo de Moda: a relação pessoa-objeto. São Paulo: Estação das Letras e Cores, 2008.

SANTOS E BARROS, José Carlos et al. Pesquisa de Marketing - Conceito de Metodologia. 3ae ed. São Paulo, Prentice Hall 2002.

SEVERINO, Antônio Joaquim, 1941 - Metodologia do trabalho cientifico, 23. ed. Ver. e atual - São Paulo, Cortez, 2007.

TEXEIRA, Luzimar. Deficiência Física: Definição, classificação, causas e características. 2010.

TREPTOW, Doris. Inventando Moda: Planejamento de coleções. 4ạ Ed. Brusque, 2007. 